\title{
SOFTWARE FOR DESIGNING OF ASYNCHRONOUS INDUCTION MACHINES FOR ADJUSTABLE SPEED ASYNCHRONOUS ELECTRIC DRIVE SYSTEMS
}

\author{
Victor S. Petrushin \\ Boris V. Kalenik \\ Electrical Machines Department \\ Odessa State Politechnic University \\ Shevchenko Avenue 1, Odessa, 270044, Ukraine \\ E-mail: victor_petrushin@ukr.net
}

\section{KEYWORDS}

Adjustable speed electric drive system, asynchronous speed induction machine, motor choosing, automatized designing of induction machine.

\begin{abstract}
Perfection of adjustable-speed electric drive systems is able with the aid of adaptation of all components, that they include, to each other. The solving of the task of based choosing of serial common-industrial asynchronous induction machine with using of complex mathematical models that include mathematical models of all components of electric drive is offered. On base of this models offered product DIMASDrive is created. The highest level of the program complex is automatized designing of special(optimized) asynchronous induction machines, that take into account significant features of operation of this machines in adjustable speed electric drive system. At this, the reducing till $50 \%$ of cost, dimensions, weight of asynchronous induction machine as composite part of adjustable speed electric drive system is reaching. Junction to producing of optimized induction machines is not connected for producer with high expenses, because constructive changes in compare to serial common industrial induction machine concerns just the stator wind of induction machine.
\end{abstract}

The basis of modern technologies is adjustable speed asynchronous electric drive system. Wide inserting of adjustable speed asynchronous electric drive system gives us capability to perfect technological processes, it also provides complex mechanization and manufacture automation, it promotes the increasing of issued production quality, decreasing of its price, growth of labor productivity, increasing of reliability and term of service of equipment(Fig.1).

In common case the composite parts of adjustable speed asynchronous electric drive system are:

input and output transformers

semiconductor converters

induction motors

reducers

mechanism-consumer(loading on adjustable speed electric drive system, that is determined by the type, quantity and mode of work of loading mechanism)

In row of cases some separate composite parts are absent.

Perfection of adjustable speed asynchronous electric drive system depends on how good are all parts adapted to each other.

In present day, in adjustable-speed electric drive systems more often serial common-industrial induction machines are applied, this asynchronous machines are designed for work in non-adjustable-speed electric drive systems. And at using of those one, it is needed to significantly increase the power of the serial machines. One of the most famous task in the designing of adjustable-speed asynchronous electric drive system is the task of based choice of serial common-industrial induction machine. The technical-economic parameters as machine itself as drive in general are depend on how right will be this task solved. Despite significant achievements in development of adjustable-speed electric drive system, at the present day clear recommendation for choosing of machines for them are absent. It is connected with significant difficulties, that appears at formalization of process of choosing of common-industrial machines for work in composition of adjustable speed electric drive system. Solving of the task of choice depends on the type, quantity and mode of work of loading drive mechanism, required range of regulating, type of semiconductor converter, kind of regulation and the law of frequency control, that are used there. For solving of task of induction machine choice is expedient to use complex mathematical models, that includes mathematical models of all components of adjustable speed asynchronous electric drive system, that allows to take into account specials of operation of motor in adjustable drive. On base of this models offered software product is created, with the aid of those it is possible to do automated choice(Fig.2). Improved calculation methods give us ability of designing and using in software product mathematical models of electromagnetic, electromechanical, energetic, heat fan processes in steady and transient regimes of machine work, calculation of additional magnetic losses, mechanical and vibroacoustic parameters. Choosing of induction machine is making by definite criterions with taking into account needed limits. As criterions can be used weight, dimensions, cost, range criterions of brought expenses and energetic 
parameters of machine or the whole drive, or these criterions with correspondent weight factor could be displace in generalized scalar(integral) criterions. In calculation of range energetic criterions of machines, used in drive with beforehand known time diagram of work. it is needed to take into account different terms of work of asynchronous induction machines on the definite frequency of rotation. Estimation of economic parameters of machine and drive work is expedient to do with account of impact of given expenses of inflation processes on criterion, because normal term of payback of induction machine are rather high(5-7 years). Results of choice changes at using of different composition of private criterions in generalized criterion and at changing of weight. Analysis of this question shows that process of choosing of asynchronous induction machine for asynchronous adjustable speed electric drive system is expedient to do stage by stage. On preliminary stage the choice of machine by heat and mechanical loading capabilities in dependence on type and quantity of loading is making.. On the next stage it is necessary to exact this choice by other technicaleconomic parameters. The task of choice should be solved with taking to account of mechanical, vibroacoustic and dynamical requirements to asynchronous induction machine of adjustable speed electric drive system. That is why, on the end stage of choice, the checking of execution of limits is producing, that are not directly connected with electromagnetic processes. To this parameters mechanical, vibro-acoustic and dynamical parameters are belonged. After execution of all dimensioned stages it is possible to say that choice of serial induction machine was made with taking into account of the main aspects of its operation in frequency electric drive.

However, how perfect would not be choice, drive with serial asynchronous induction machine won't be optimal. It is expedient to perfect the adjustable-speed electric drive system by purposed adaptation of used there machine and by designing of special asynchronous induction machines. By this, electrical machines with the best energetic, weight and dimension parameters in comparison to non-adapted ones are creating. Automated designing of asynchronous induction machine is doing with using of program complex called DIMASDrive.

Technical premises that provide advantages of adapted machines above the serial machines are:

exception of requirements to start characteristics(there is no task of provision multiplicity(frequency rate) of start and maximal moments), in connection with what may correspondent shape of rotor groove(refusal from deep grooves) be applied, that provide minimal rotor circuit resistance and smaller induction of dispersion.

Required rotation frequency of manufacturing mechanism. That is determined by frequency of machine power supply, number of poles of stator wind of asynchronous induction machine and transmission number of reducer. It is possible to provide at different combinations of these three quantities.

Possibility of some reducing of overloading ability of asynchronous induction machine, because drive management system trace parameters of voltage and current supplied to the machine.

Using of effective systems of auto-, and at the necessity, forced cooling with optimized rotation frequency of the fan.

Capability of choosing of optimal relation of nonstandard significances of voltage and frequency of designing machine, that differs from basic and coordinated with nominal significances of converter, that allows to reduce the weight and dimensions.

Reinforcement of electrical insulation of stator wind coil with the purpose of dependence of stator from impulse overvoltage.

Using of correspondent bearing with taking into account as high speeds of rotation as appearing of parasite currents from highfrequency commutation.

In dependence from technical task, task of designing of adjustable induction machine can have two statements. One of them supposes designing for definite by type and quantity of loading with correspondent frequency management law in command range of regulation. The second one - designing of adjustable induction machine that satisfies to different types of loading. By this way designing of machine series ROTEC by Siemens was made. In this case range of regulation is definite, in what constant commanding of power is maintaining or, otherwise, the power at what command range of regulation could be determined. Adjustable induction machines could be designed in kind of series(ROTEC) or in kind of electrical modification series, built on base of basic performance. Solving of task of modification designing is doing by purposed recalculation with using of optimized procedures of basic serial machine.

Basic principles and methodology of asynchronous induction machines are based on system approach and are defined with taking into account of essential specificity of their work in composition of electric drives as in steady as in dynamical modes. System approach provides consideration of asynchronous induction machine in cooperation with other elements of asynchronous adjustable speed electric drive system: strength converter part, management and settlement system, perform organ of work machine. Efficiency of system approach in designing of asynchronous induction machine is based on count of features of separate components of electric drive, character of relations and connection between this two components. Thanks to this adequacy of mathematical model and, correspondently, quality of project synthesis of asynchronous induction machine are increasing. Using of system approach allows to realize complex analysis of designing of asynchronous induction machine. On 
base of what, all main for project synthesis aspects of device and operation of asynchronous induction machine are considering. System approach gives us opportunity to perform:

complex count of all needed sets of project factors in their interrelation and interference; engineering and application of mathematical models, that takes into account variations of parameters in the whole adjust range and other features of work or asynchronous induction machine in adjustable electric drive;

justification and application of rational decomposition of project mathematical model and model of object of designing, processes of project synthesis and optimization;

realization of effective methods of optimization;

system organization of technology of process of project synthesis of asynchronous induction machine

Project mathematical models of asynchronous induction machine take into account polyharmonic composition of voltage or variable quantity current and frequency, variation of machine parameters in process of adjustment and row of other project features. Semiconductor converters, that differs by types, force schemes, kinds of adjustment, management laws and so on, are represented by different mathematical models. Loadings of electric drive have different laws of variations of moments from rotation frequency and different levels. They can be continuous or circle action. All that finds a reflection in mathematical models of loadings.

Work of machines in systems with semiconductor converters have significant specificity, that is the reason of the appearance of new requirements to technicaleconomic parameters of asynchronous induction machine, and, as a result, the task of designing of machines for indicated systems has been grown to independent problem, that includes the round of questions that are connected with determination of optimal machine parameters. For solving of tasks of project synthesis and optimization of this machines can not be applied standard methods and software, developed for induction machine for common industrial purpose.

In designing of asynchronous induction machine this features and requirements are taking into account:

complex mathematical models in system of calculation are used, that includes to themselves models of all interaction components of electric drives, and not just machine models, as it is doing in system of calculated designing of common-industry induction drives.

asynchronous induction machines are designing not for one nominal point of work, as common industry machines, but for command adjustment range and in development of the volume of searching and checking of calculation.

In each work point of asynchronous induction machine consumes definite by qualityquantitative composition of polyharmonic voltage or current, that depends on type, kind of adjustment, converter management law and working with determined loading moment.

In different work points of adjustment range of significance of parameters of machine replacement schemes, that are determined with taking into account replacement of currents in winds and saturation of magnetic circuit, are different.

Variations of equivalent heat schemes of replacement of asynchronous induction machine because of changing of intensity of cooling at rotation frequency adjustment are observing.

In designing of asynchronous induction machine for drives with semiconductor converters the same criterions that in choosing of serial induction machines for those drives are used. The special range criterions of optimality - energetic machine parameters and indicated expenses cause the specificity of their determination. In particular, energetic parameters - efficiency factor and power factor, indicated expenses should be considered in view of average significances for definite command adjustment range. The energetic composite part expenses will exceed composite part expenses connected with capital expenses in ten times, that is why question of optimization exactly energetic composite part is especially famous. At this, it is needed to take into account ambiguity of increasing of efficiency factor and power factor: reducing of cost of active losses in ten times is more effective then reducing of cost of reactive energy compensation.

The task of adaptation of parts of asynchronous adjustable-speed electric drive system to specific conditions of work should be solved as a task of structure-parameter optimization.

Labour content of designing task is caused not only by necessity of formation of plenty rational structures of asynchronous induction machine, but else, by necessity of solving of parametrical optimization for each shaped structure task. The direction of tasks of structure synthesis has two branches: interior(related to the machine) and exterior(related to the drive system). The task of parametrical optimization is in determination of significance set of managed variables of some shaped structures of electric drive system and asynchronous induction machine, included there, at what the purpose function has the best significance. At this, all requirements and limits that were dimensioned in designing task should be executed. A number of asynchronous induction machines with optimized parameters is information basis for choice of optimal variant of asynchronous induction machine.

System approach provides consideration of all aspects of asynchronous induction machine operation. That's 
why at project synthesis of asynchronous induction machine the row of subsystems is using, with the aid of what the checking calculations are making. To this number of mechanical and vibro-acoustic parameters of non-steady work regimes are treating. Project mathematical models as models of optimized-searching calculations are complex and are compounded of mathematical models and drive of elements and count of considered above specificity are executing there.. The task of conditional optimization is solving on base of combination concession methods on criterions and limits relaxation.

From above dimensioned, using of information technologies of automated project synthesis, applied mathematical and program provision DIMASDrive allows to realize the designing of series of asynchronous induction machine on base of careful analysis of consumption market; designing of asynchronous induction machine for using in asynchronous adjustable-speed electric drives of concrete electromechanical systems; redesigning of induction machines, used in the present time in definite adjustable-speed electric drive systems with the target of their adaptation to specific work conditions.

In the present time are offered asynchronous induction machines, that designed for frequency fields $30-90 \mathrm{~Hz}$, despite converters allow to work on higher frequencies (till 400-500 Hz). Designing of asynchronous induction machine for high frequencies would leads to reducing of weight and dimensions and by that, to the reducing of the cost of the machine. It means, that modifications of asynchronous induction machines of as low-frequency as high-frequency are possible. Expediency of using in concrete adjustable-speed electric drive system one or another modification is determining by economical efficiency.

Example: designing of adjustable induction machine with loading of $35 \mathrm{Nm}$ and adjustment field 500-5000 rpm(lifting-transport mechanisms) is needed. It's possible just with serial induction machine of $180 \mathrm{~S} 2$ dimension or more, because all smaller serial machines can't allow it in connection with exceeding of admitted temperature of their parts(particularly stator wind). But after optimization and machine of smaller dimension 132M6 could corresponds to command requirements. Optimization is in redesigning of wind to frequency of $152 \mathrm{~Hz}$. Converter is tuning to this correspondent base frequency too. By this we receive suitable adjustable induction machine(optimized 132M6) with the weight of $78 \mathrm{~kg}$ but not serially producible $180 \mathrm{~S} 2$ with the weight of $148 \mathrm{~kg}$, the production cost of what is higher because of high weight. Even bigger weight reducing is possible at designing of high-frequency modifications of adjustable induction machine.

Competition.

On this moment there is not alternative software. That allows to do designing of a induction machines by optimization of serial asynchronous induction machines and adapting them to adjustable-speed electric drive system. Thanks to optimization in designing of low- frequency modifications of asynchronous induction machines is reaching reducing of this machine parameters:

cost: till 20-25\%

dimensions: till $20 \%$

weight: till $20 \%$

the line of firms issue low-frequency modifications. Application of offered software provides automated designing of these low-frequency modifications. Excepts that, with help of this software is possible to design high-frequency modifications of asynchronous induction machines. High-frequency modifications of asynchronous induction machines, designed with aid of DimasDrive, provide reducing of this machine parameters:

\section{cost: till $50 \%$}

dimensions: till $50 \%$

weight: till $50 \%$

or at the same weight and dimensions - increasing of power till $40 \%$.

With help of software is possible to make designing of asynchronous induction machines for new adjustablespeed electric drive systems and too optimization of already existing adjustable-speed electric drive systems by the way of redesigning used there induction machines.

\section{AUTHOR BIOGRAPHIES}

VICTOR S. PETRUSHIN in 1968 ended Odessa Politechnic University by speaciality of electric machines and apparatus. In 2002 obtained doctor degree on theme: "Design synthesis of high-effective adjustable induction motors by a power up to $400 \mathrm{~kW}$ ". This time is working in the same university as chief of electric machines faculty of Odessa State Politechnic University.

GRIGORII G. OSIPOV in 1969 ended Odessa engineering-construction university by spatiality of engineering and construction. This time is working as chief of of manufacturing department of capital construction management.

BORIS V. KALENIK in 2005 ended physicalmathematical faculty of theoretical lyceum and entered electric machines and apparatus faculty of Odessa State Politechnic University where still is studiing.

\section{REFERENCES}

Petrushiv V.S., Ryabinin S.V., Yakimets A.M., "DIMASDrive" software for work analysis, choice and design of cage induction motors for adjustable-speed electric drives (state registration number PA 4065), Kyiv, Ministry of education and science of Ukraine, State department of intellectual property, 26.03.2001.

V.I. Radin, J. Londin, V.D. Rozenkop and others "Unified "Interelectro" series of induction motors" /; Under edition by V.I. Radin. Moscow: Energoatomizdat (in Russian), 1990. $416 \mathrm{p}$. 
Bespalov V.Y. Problems of theory, simulation and design of electric machines working in systems with semiconductor converters. $/ / 5^{\text {th }}$ International conference UEES'01, Miedzyzdroje, Poland, 05-08 Sept. 2001, pp. $147-154$.
Z.M. Zhao, C.C. Chan, E.W.C. Lo, "A novel induction machine design suitable for inverter-driven variable speed systems", IEEE Trans. On Energy Conversion, vol.15, No.4, Dec.2000, pp. 413-420.

\section{FIGURES}

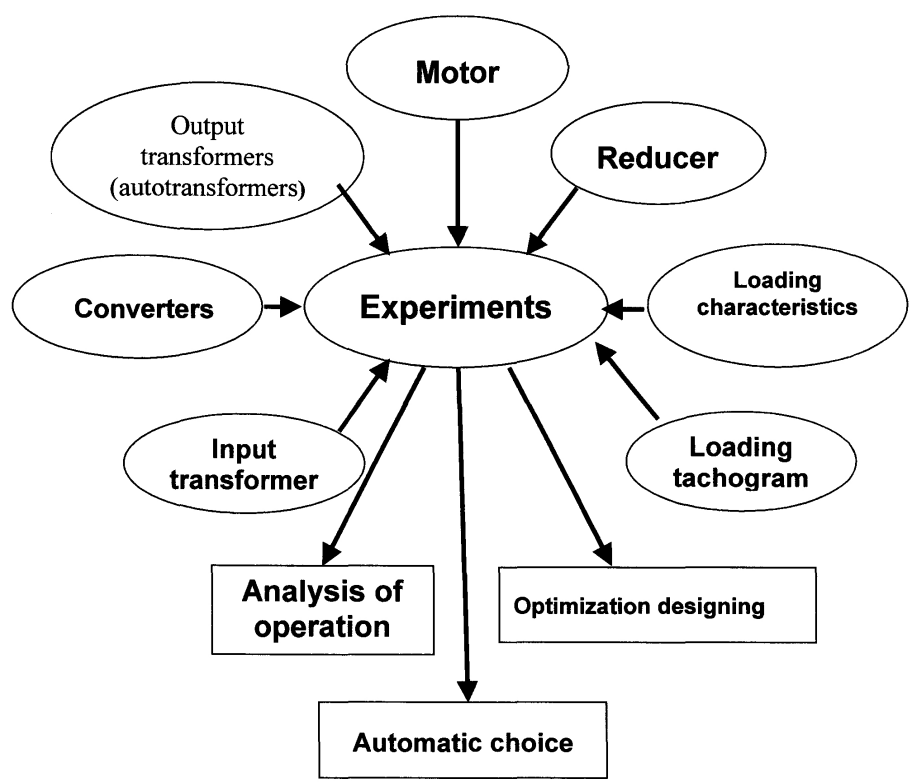

Figure 1: Induction motor in frequencial electrical drive. Scheme of program

\section{COMPOSITION OF PROGRAMME MODULES OF THE COMPLEX}

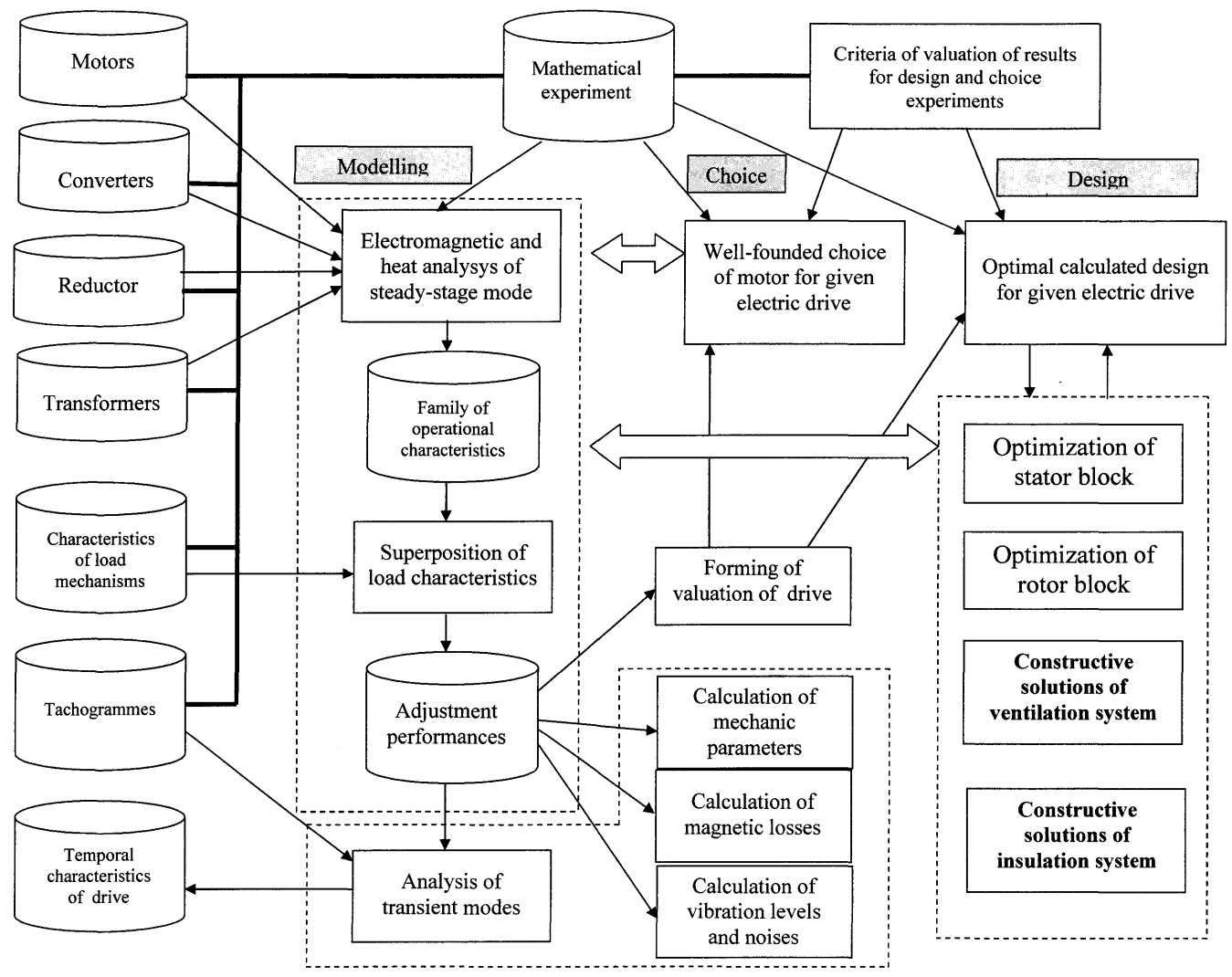

Figure 2: Composition of the program modules of the complex 